\title{
A Longitudinal Study on the Changes in Mental Health of Healthcare Workers during the COVID- 19 Pandemic
}

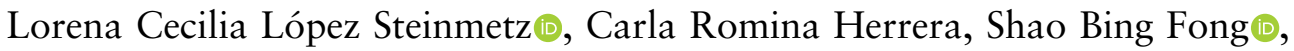 \\ and Juan Carlos Godoy (D)
}

\begin{abstract}
Objective: This study examines Argentinean health care workers in order to 1) test self-perceived job performance levels and the presence of psychological symptoms compatible with common mental disorders, and 2) examine withinperson changes in general discomfort and psychological distress, adjusting for demographic factors, region, and health-related factors during two time points of the COVID-19 pandemic.

Method: This longitudinal study comprised 305 healthcare workers who completed a survey at two time points approximately 4 months apart. We used the General Health Questionnaire and the Kessler Psychological Distress Scale to measure mental health outcomes. To address the first aim we calculated differences (Student's $t$ test for paired samples) and correlations (Pearson's $r$ coefficient). To address the second aim we used fixed effects model by means of a multilevel approach, a linear model that considers dependency in the data. Results: Self-perceived job performance deteriorated across time. From the first measurement to the four-month follow-up, more health care workers presented common mental disorders ( $40 \%$ vs $45.57 \%$ ), depression, and/or anxiety $(52.46 \%$ vs $62.62 \%$ ). A meaningful worsening of mental health was observed in healthcare
\end{abstract}

\footnotetext{
Lorena Cecilia López Steinmetz, Ph.D. Prof. Dr. López Steinmetz is a postdoctoral fellow from the National Council of Scientific and Technical Researches (CONICET, Argentina) at the Institute of Psychological Researches (IIPsi-UNC-CONICET). She is a researcher in the Laboratory of Psychology, from the IIPsi-UNC-CONICET, as well as a Professor at the University Siglo 21 (Córdoba, Argentina). Prior to these positions, she was a Professor at the Santiago del Estero Catholic University, San Salvador Academic Department (UCSE-DASS, Jujuy, Argentina). In addition, she held roles as a Resident in the specialties of Clinical and Community Psychology at the Néstor Sequeiros Psychiatric Hospital (Jujuy, Argentina), a fellow from the Carolina Foundation (Madrid, Spain), and a doctoral fellow from the CONICET. Carla Romina Herrera, Ps. She is a Psychologist at the Emergency Ward of the Hospital Wenceslao Gallardo from the Jujuy province, Argentina. Previously, she was a Psychologist at the National Ministry of Health (Argentina). Shao Bing Fong, Ph.D. Dr. Fong is a researcher at the University of Rennes 1 (Rennes, France) and maintained affiliations as an alumni with University of Melbourne (Parkville, Australia) where she obtained her doctorate and worked as a researcher. Juan Carlos Godoy, Ph.D. Prof. Dr. Godoy is a researcher at the Faculty of Psychology from the National University of Córdoba (UNC) and the National Council of Scientific and Technical Researches (CONICET, Argentina). He is the head of the Laboratory of Psychology, from the Institute of Psychological Researches (IIPsi-UNC-CONICET). Likewise, he is a Professor at the Faculty of Psychology from the UNC, and the executive editor of the Journal of Argentinean Behavioral Sciences (Revista Argentina de Ciencias del Comportamiento).

Address correspondence to Lorena Cecilia López Steinmetz. Boulevard de la Reforma esquina Enfermera Gordillo, s/n, 2do Piso, Facultad de Psicología, Ciudad Universitaria, Córdoba 5000, Argentina.

E-mail: cecilialopezsteinmetz@unc.edu.ar
} 
workers who expressed concern about being infected with COVID-19, whether asymptomatic (greater general discomfort and psychological distress) or symptomatic (greater general discomfort). Likewise, there were significant interactions between a history of mental disorder and concern about COVID-19 infection.

Conclusions: Among healthcare workers, the uncertainty about the COVID-19 infection may have larger negative mental health impacts than actually being infected.

The COVID-19 outbreak which started in late 2019 in China has led to an unprecedented pandemic. As of November 6, 2020, 6,351 COVID-19 cases per million population and 159 deaths per million population have been reported worldwide. On the same date, Argentina was hit hard by this disease, reporting a total of 26,842 cases per million population, but based only on 69,317 tests per million population, and with 723 deaths per million population (Worldometer, 2020). This pandemic is one of the most globally traumatic events since historical times and poses great challenges in all population groups. Notably for healthcare workers who are under highly stressful conditions, often working extra shifts and hours longer than usual to assist high volume patient demand. While some cross-sectional reports on healthcare workers' mental health during the COVID-19 pandemic are available (Muller et al., 2020; Pappa et al., 2020), longitudinal analysis on the withinperson changes of mental health outcomes among healthcare workers are lacking. Thus, in this study, we have addressed two main aims: (1) to test self-perceived job performance levels and the presence of psychological symptoms compatible with common mental disorders in Argentinean healthcare workers, at two time points during the COVID-19 pandemic; and (2) to examine changes in the levels of general discomfort and psychological distress in healthcare workers, adjusting for main demographic factors, region, and some relevant healthrelated factors, during the COVID-19 pandemic.

\section{METHODS}

\section{Design}

This study used a longitudinal design, with two repeated measures. Sampling was one of convenience. The inclusion criteria were being a healthcare worker (irrespective of their training, e.g., doctors, nurses, psychologists, technicians, cleaners, administrative staff or any other profession) and working during the COVID-19 pandemic in health institutions, public or private, from the Argentinean provinces of Buenos Aires or Jujuy. We have chosen these two provinces in order to compare between the main metropolitan area (Buenos Aires), having high rates of COVID-19 cases during the first months of the pandemic, and an area within the country (Jujuy) where almost no cases of this disease were reported during the first months of the pandemic.

The first measurement started on April 2 (i.e., 14 days after the Argentinean quarantine started) through May 30, 2020. The second measurement (follow-up) was carried out during the second half of September 2020. The outcome variables were (i) general discomfort and (ii) psychological distress. The predictors that we analyzed were: age, sex, region, mental disorder history, and COVID-19 contagion. In addition, we descriptively analyzed self-perceived job performance levels and levels of psychological symptoms compatible with common mental disorders. 


\section{Procedure}

Collection procedure was carried out online, by using the LimeSurvey software (UNC license). For the first measurement, this study was disseminated by e-mail and the WhatsApp mobile application lists; it was also disseminated multiple times on social networks and then shared, retweeted, and liked by many people. The invitations to participate contained a brief mention about the general aim and design, general inclusion criteria, and the link for the online survey. No personal identification data was asked of participants during the survey, but an e-mail address and a cellphone number was required for the follow-up. During September $15^{\text {th }}$ to $30^{\text {th }} 2020$, participants were contacted via e-mail or WhatsApp, with a brief invitation to complete the online survey for the second time. In both the first and the second measurements, upon accessing the survey, participants were initially presented with the information sheet and informed consent form. Written informed consent was obtained from all subjects.

\section{Ethics}

This study was approved by the Ethics Committee of the Institute of Psychological Research, Faculty of Psychology, National University of Córdoba (CEIIPsi-UNCCONICET; comite.etica.iipsi@psicologia. unc.edu.ar) on April 2, 2020. The authors assert that all procedures contributing to this work comply with the ethical standards of the relevant national and institutional committees on human experimentation and with the Helsinki Declaration of 1975 , as revised in 2008 .

\section{Variables and instruments}

\section{General discomfort}

We used the GHQ-12 (General Health Questionnaire; Goldberg et al., 1997) in its
Argentinean validation (Cronbach's alpha $=$ 0.80; Burrone et al., 2015). This instrument evaluates the general dimension of selfperceived health (hereafter general discomfort), which includes dimensions related to unspecific psychological discomfort, and social functioning and coping. We used the dichotomous scoring $(0-0-1-1)$ whose range of scores is between 0 and 12 , rather than the Likert method [0-1-2-3] or the C-GHQ method [0-1-1-1] (for more details on these methods see, e.g., Goldberg et al., 1997). Higher scores indicate higher general discomfort. For this form of scoring, the cutoff scores indicating common mental disorders are 4 or 5 (Goldberg et al., 1997). We adopted the higher cutoff score (i.e., $>5$ ).

\section{Psychological distress}

We used the K-10 (Kessler Psychological Distress Scale; Kessler \& Mrozek, 1994) in its Argentinean validation (Cronbach's alpha $=0.88$; Brenlla \& Aranguren, 2010). This instrument is a dimensional measure of nonspecific psychological distress (hereafter psychological distress), which evaluates symptoms related to depression and anxiety. The range of the $\mathrm{K}-10$ scores is between 0 and 50 . Higher scores indicate higher psychological distress. The K-10 has the ability to discriminate DSM-IV cases from non-cases (Kessler et al., 2002), but there are no cutoff scores specific to the Argentinean population. Thus, we adopted the cutoff score $>20$ (Donker et al., 2010) for determining between cases and non-cases of any depressive and/or anxiety disorder.

\section{Age}

We used a single item to ask for the participants' age. For data analysis, we grouped age into two broad categories: Younger (participants $<40$ years old), Older (participants $\geq 40$ years old). 
Sex

We used a single item, with a dichotomous answer, to ask for the participants' biological sex: Man, Woman.

\section{Region}

We used a single item to ask participants' site of residence (hereafter region or area). The answer options were: Jujuy, Buenos Aires, Other. Those who chose this last option were excluded because they did not meet one of the inclusion criteria. For data analysis, we named the categories Jujuy and Buenos Aires as inside the country and metropolitan area, respectively.

\section{Mental disorder history}

We used a single item to ask participants "Before the pandemic started, have you ever been diagnosed with a mental problem (for example: depression, anxiety, obsession, or any other)?." Answer options were dichotomous: No (absence), Yes (presence).

\section{COVID-19 Contagion}

In the follow-up survey, we included a single item to ask participants "During the current pandemic, were you infected with the COVID-19?." The answer options were: No, I was not infected with the COVID-19; I don't know if I was infected with the COVID-19 and I have no symptoms of the disease; I don't know if I was infected with the COVID-19, but I have symptoms of the disease; Yes, I got sick with the COVID-19.

\section{Self-perceived Job Performance}

We used a single item to ask participants to indicate how they self-rated their job performance at that time. Answer options were: Excellent, Very good, Good, Bad, Very bad.

\section{Statistical Analyses}

We performed all data analysis with $\mathrm{R}$ version 3.6.2 ( $\mathrm{R}$ Core Team, 2020). The level of significance was set at $p \leq .05$. We report exact $p$-values, except for $p$-values under .001 , where we report as $p<.001$. Score distributions of the outcome variables were in the range of acceptable values for skewness and kurtosis $(-1$ to 1 and -3 to 3 , respectively; Brown, 2006). Since all items were marked as mandatory during data collection, there were no missing data to handle.

To address the first aim of this research, we provided descriptive measures (percentages, mean, and standard deviation). Likewise, we analyzed differences (with Student's $t$ test for paired samples) and correlations (with Pearson's correlation coefficient) for the scores of each mental health state indicator between the two measurements.

To address the second aim of this research, we ran mixed effects modeling by means of a multilevel approach for (i) general discomfort and (ii) psychological distress, as the outcome variables. In this multilevel approach, the method we used was a multilevel linear model that handles dependent data by explicitly modeling the dependency (Field et al., 2012). However, as random effects proved to be non-significant (see Results section below), all models we had run were fixed. In the models we analyzed, in addition to the within-person factor (changes in each mental health state indicator between the first measurement and the follow-up), we included the following between-group factors: age (younger, older), sex (man, woman), region (inside the country, metropolitan area), mental disorder history (absence, presence), and COVID-19 contagion (no, does not know and has no symptoms, does not know but has symptoms, yes). Before building the models, we have set non- 
orthogonal contrasts for the predictor having more than two conditions. We established the condition no (i.e., not having got infected with the COVID-19) as the baseline. The contrasts compared the baseline vs each one of the remaining conditions of the COVID19 contagion. We opted for using nonorthogonal contrasts to discriminate which particular situations (from less to most serious) had the greatest negative impacts on workers' mental health when compared to the "less serious" situation (assumed as our user-defined baseline category), in order to be able to propose interventions, simple and affordable, in cost-benefit terms for a developing country as Argentina.

For each outcome variable, the first model only contained the intercept. We have built up the models by adding one predictor at a time in order to test the overall main effect of each predictor and, then, we have built up the models to test all the possible interactions for two-predictors combinations. For the analysis of mixed effects modeling we have used the nlme package (Pinheiro et al., 2020) and specified maximum likelihood (ML) as a method. We have compared the fit of the models using two criteria: The Akaike Information Criterion (AIC) and the Log-Likelihood (logLik). For meaningful predictors in the best fitting model, we have calculated effect sizes (ES) by using the DSUR.noof package (Field et al., 2012).

\section{RESULTS}

\section{Participants}

Three hundred thirty-nine healthcare workers participated during the first measurement. For the second measurement, the attrition was at $10.03 \%$. Based on information provided (during individual contacts via telephone) by healthcare workers that failed to complete the survey during the follow-up, the main reasons for the attrition that they referred were: (1) mainly, work overload and exhaustion due to the work demand related to the
COVID-19 pandemic, and (2) being sick with COVID-19, having severe symptoms that made it impossible for them to be able to respond to the survey. However, this second reason was mentioned by very few participants compared to those mentioning the first reason. Up to the time we finished the follow-up, none of the participants of this study had died from COVID-19. In this paper, we focused only on the sample of 305 healthcare workers that completed the online survey for the two repeated measures. In this entire sample, $44.92 \%$ were from the metropolitan area, $79.34 \%$ were women, and the mean age was 41.26 (s.d. 9.37). With regards to the line of work, $75.41 \%$ healthcare workers working in one $(50 \%)$ or more $(50 \%)$ services are involved in the following close contact patient assistance: emergency ward (113), inpatient settings (81), ambulance (33), and/or outpatient consultations (124). The remaining $24.59 \%$ of the sample was committed to providing online patient assistance. Additional descriptive information on the sample is in Table 1.

\section{Self-perceived Job Performance}

In the first measurement, most healthcare workers perceived their job performance as excellent or very good (accumulated $56.40 \%$ ), while in the followup, most of them perceived their job performance as good or bad (accumulated $55.41 \%$; Figure 1 ).

\section{Psychological Symptoms Compatible with Common Mental Disorders}

In the first measurement, $40 \%$ of healthcare workers had scores compatible with common mental disorders (as measured by the GHQ-12) and $52.46 \%$ had scores compatible with any anxiety or depressive disorder (as measured by the K-10). In the follow-up, these percentages were raised to $45.57 \%$ and $62.62 \%$, respectively. Table 2 shows this information, but discriminated by regions. 
TABLE 1. Description of the Sample $(N=305)$

\begin{tabular}{llc}
\hline \multirow{2}{*}{ Variables } & & \multicolumn{1}{c}{$\begin{array}{c}n(\%) \text { or } M(s . \\
d .)\end{array}$} \\
\hline Region of residence & Metropolitan & $137(44.92)$ \\
& Inside the country & $168(55.08)$ \\
Biological sex & Woman & $242(79.34)$ \\
& Man & $63(20.66)$ \\
Age & $41.26(9.37)$ & $150(49.18)$ \\
Age groups & Younger $(<40$ years old $)$ & $155(50.82)$ \\
& Older $(\geq 40$ years old) & $43(14.10)$ \\
Mental disorder history & Yes & $262(85.90)$ \\
& No & $138(45.25)$ \\
COVID-19 contagion at the & No, he/she was not infected with the COVID-19 & $99(32.46)$ \\
follow-up & It is unknown if he/she was infected with the COVID-19 and has no symptoms & $20(6.56)$ \\
& of the disease & $48(15.74)$ \\
\hline
\end{tabular}

Note: $n(\%)$ : absolute frequencies (percentages); M: Media; s.d.: standard deviation.
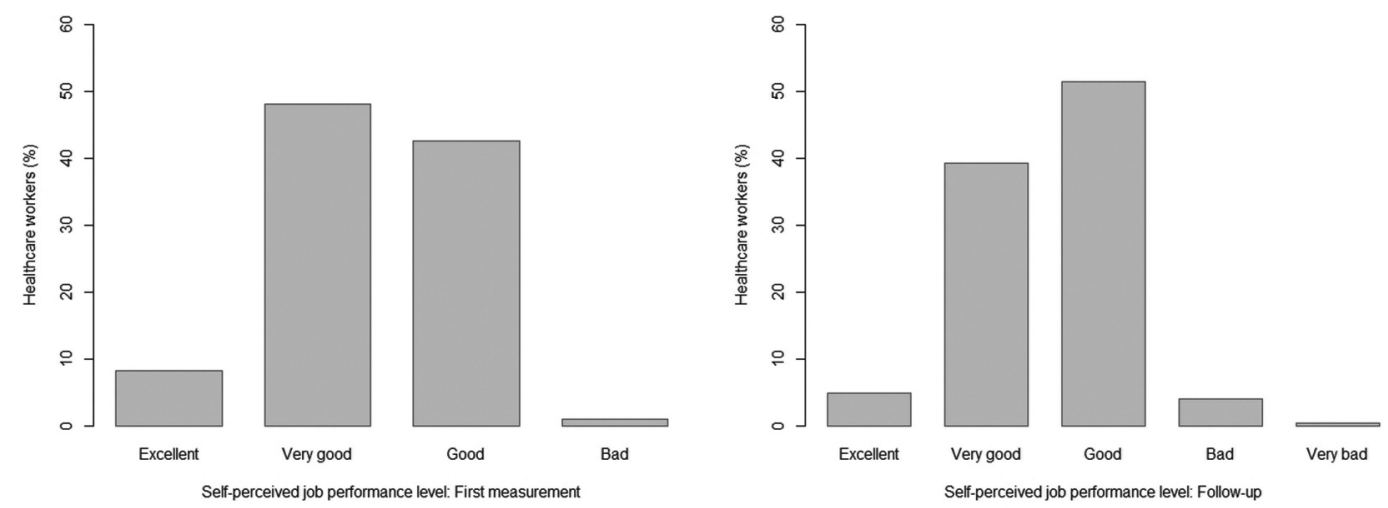

FIGURE 1. Self-perceived job performance in healthcare workers ( $N=305)$. Left side: Self-perceived job performance in healthcare workers in the first measurement. Right side: Self-perceived job performance in healthcare workers in the follow-up. Note: Data are expressed as percentages.

General Discomfort and Psychological Distress during the Two Measurements

Mean scores during the first measurement and the follow-up were significantly different in psychological distress $\left(t_{(304)}=-4.39\right.$, $p<.001)$, but not in general discomfort $\left(t_{(304)}\right.$
$=-1.37, p=.17)$. The mean scores during the first measurement and the follow-up were of 22.39 (s.d. 7.66) and 24.28 (s.d. 8.33) in psychological distress and 4.93 (s.d. 3.08) and 5.23 (s.d. 3.57) in general discomfort, respectively. Table 3 presents the mean scores of each mental health state indicator corresponding to both measurements by age, sex, region, 
TABLE 2. Healthcare Workers from the Metropolitan Area and from inside the Country with Scores Compatible with Common Mental Disorders and Depressive and Anxiety Disorders, during the First Measurement and the Follow-up

\begin{tabular}{lcccc}
\hline & \multicolumn{2}{c}{ Common mental disorders (GHQ-12) } & \multicolumn{2}{c}{ Depressive and/or anxiety disorders (K-10) } \\
\cline { 2 - 5 } Area $(\boldsymbol{n})$ & $\mathbf{1}^{\text {st }}$ measurement $(\%)$ & $\mathbf{2}^{\text {nd }}$ measurement $(\%)$ & $\mathbf{1}^{\text {st }}$ measurement $(\%)$ & $2^{\text {nd }}$ measurement $(\%)$ \\
\hline Metropolitan (137) & 40.88 & 45.98 & 59.12 & 66.42 \\
Inside the country (168) & 39.29 & 45.24 & 47.02 & 59.52 \\
\hline
\end{tabular}

Note: Common mental disorders: scores compatible with common mental disorders as measured by the GHQ-12 (General Health Questionnaire; Goldberg et al., 1997), by the standardized cutoff score > 5 (Goldberg et al., 1997). Depressive and/or anxiety disorders: scores compatible with any depressive and/or anxiety disorder as measured by the K-10 (Kessler Psychological Distress Scale; Kessler \& Mrozek, 1994), by the cutoff score > 20 (Donker et al., 2010).

TABLE 3. Mean Scores of General Discomfort and Psychological Distress in Each Measurement by Age, Sex, Region, Mental Disorder History, and COVID-19 Contagion in Healthcare Workers $(N=305)$

\begin{tabular}{|c|c|c|c|c|}
\hline \multirow[b]{2}{*}{ Outcome variable } & \multirow[b]{2}{*}{ Factors } & \multirow[b]{2}{*}{ Categories } & \multicolumn{2}{|c|}{ Scores } \\
\hline & & & $\begin{array}{c}1^{\text {st }} \text { measurement } \\
M(s . d .)\end{array}$ & $\begin{array}{l}\text { Follow-up } \\
M(s . d .)\end{array}$ \\
\hline \multirow[t]{12}{*}{ General discomfort } & Age & Younger & $5.47(3.01)$ & $5.49(3.51)$ \\
\hline & & Older & $4.41(3.07)$ & $4.99(3.61)$ \\
\hline & Sex & Man & $4.43(3.22)$ & $5.16(3.78)$ \\
\hline & & Woman & $5.06(3.03)$ & $5.25(3.52)$ \\
\hline & Region & Metropolitan & $5.12(2.83)$ & $5.19(3.12)$ \\
\hline & & Inside the country & $4.78(3.27)$ & $5.27(3.90)$ \\
\hline & Mental disorder history & Absence & $4.87(3.12)$ & $5.15(3.57)$ \\
\hline & & Presence & $5.28(2.82)$ & $5.72(3.52)$ \\
\hline & COVID-19 contagion & No & $4.78(3.11)$ & $4.59(3.69)$ \\
\hline & & Does not know and has no symptoms & $4.91(3.04)$ & $5.67(3.35)$ \\
\hline & & Does not know but has symptoms & $5.40(3.03)$ & $7.60(3.82)$ \\
\hline & & Yes & $5.21(3.15)$ & $5.21(3.06)$ \\
\hline \multirow[t]{12}{*}{ Psychological distress } & Age & Younger & $23.77(7.62)$ & $24.91(8.26)$ \\
\hline & & Older & $21.05(7.48)$ & $23.68(8.37)$ \\
\hline & Sex & Man & $20.75(7.29)$ & $23.49(9.09)$ \\
\hline & & Woman & $22.82(7.71)$ & $24.49(8.12)$ \\
\hline & Region & Metropolitan & $22.89(6.55)$ & $23.98(6.46)$ \\
\hline & & Inside the country & $21.98(8.46)$ & $24.52(9.59)$ \\
\hline & Mental disorder history & Absence & $21.92(7.57)$ & $23.73(8.26)$ \\
\hline & & Presence & $25.26(7.71)$ & $27.63(8.00)$ \\
\hline & COVID-19 contagion & No & $22.25(8.03)$ & $23.21(8.45)$ \\
\hline & & Does not know and has no symptoms & $22.46(6.80)$ & $25.65(7.81)$ \\
\hline & & Does not know but has symptoms & $24.55(10.03)$ & $27.95(10.26)$ \\
\hline & & Yes & $21.75(7.25)$ & $23.02(7.48)$ \\
\hline
\end{tabular}

Note: M: Mean. s.d.: standard deviation.

mental disorder history, and COVID-19 contagion.

We found positive and statistically significant relationships in the scores of general discomfort $(r=.34, p<.001)$ and in the scores of psychological distress $(r=.56, p<$ .001 ) between the first measurement and the follow-up. 


\section{Fixed Effects Modeling: General Discomfort}

We evaluated the need to analyze nested models by regions, but the inclusion of random effects was not statistically significant for general discomfort $\left(A I C_{\text {start }}=1644.34, A I C_{\text {final }}=\right.$ $1646.34, p>.99)$. Thus, the models that we built up included only fixed effects $\left(A I C_{\text {start }}=\right.$ 3170.53). We found a significant main effect of the age $\left(\chi_{(6)}^{2}=6.39, p=.01 ; A I C=3166.26\right.$, $\log L i k=-1577.13)$ on general discomfort. The scores of general discomfort were higher in the younger age group ( $<40$ years old), although with a small effect size $(E S=0.16)$. There was also a main effect of the COVID-19 contagion $\left(\chi_{(12)}^{2}=8.94, p=.03 ;\right.$ AIC $=3166.79, \log L i k=$ -1571.39 ) on general discomfort, but we did not interpret this main effect because there is a significant interaction involving this main effect, which supersedes it (see below). On the other hand, the scores on general discomfort in the first measurement and the follow-up were similar $\left(\chi_{(5)}^{2}=1.89, p=.17 ;\right.$ AIC $=3170.65$, $\log L i k=-1580.32)$. Likewise, the scores on general discomfort were similar between the sexes $\left(\chi^{2}(7)=0.63, p=.43 ;\right.$ AIC $=3167.63$, $\log L i k=-1576.81)$, between the regions $\left(\chi^{2}\right.$
(8) $=0.02, p=.89 ;$ AIC $=3169.61, \log L i k=$ $-3204.92)$, and by the absence or the presence of mental disorder history $\left(\chi_{(9)}^{2}=1.88, p=.17\right.$; $A I C=3169.73, \log L i k=-1575.87)$.

However, there were significant interaction effects between time (the within-person factor $)$ and the COVID-19 contagion $\left(\chi_{(19)}^{2}=\right.$ 9.88, $p=.02 ; A I C=3167.95, \log L i k=$ $-1564.98)$ on general discomfort. The contrasts revealed that, compared to those who had not been infected with the COVID-19, the general discomfort significantly increased from the first measurement to the follow-up in those who did not know if they had been infected with the COVID-19, whether they had no symptoms of the disease $\left(b=1.09, t_{(297)}=\right.$ $2.16, p=.03, E S=0.12$ ) or if they had it ( $b=$ $\left.2.33, t_{(297)}=2.55, p=.01, E S=0.15\right)$. On the contrary, there were no significant differences in the general discomfort during both measurements when we compared to those who had not been infected with the COVID-19 and those who had gotten sick with COVID-19 $\left(b=0.13, t_{(297)}=0.21, p=.83\right)$.

The remaining interactions that we tested were not meaningful $(p>.05$; data not shown). Table 4 summarizes the model best fitting the data on general discomfort.

TABLE 4. Model Best Fitting the General Discomfort in Healthcare Workers $(N=305)$

\begin{tabular}{|c|c|c|c|c|c|}
\hline \multirow[b]{2}{*}{ Predictors $^{\mathrm{a}}$} & \multirow[b]{2}{*}{$b$} & \multirow[b]{2}{*}{$t_{(d f)}$} & \multirow[b]{2}{*}{$p^{\mathrm{b}}$} & \multicolumn{2}{|c|}{$95 \% \mathrm{CI}$} \\
\hline & & & & Lower & Upper \\
\hline Intercept & 4.75 & $8.64_{(297)}$ & $<.001^{* * *}$ & 3.68 & 5.81 \\
\hline Time & -0.04 & -0.07 (297) & .95 & -1.28 & 1.19 \\
\hline Age (younger) & -1.08 & $-2.78(297)$ & $.006^{* *}$ & -1.83 & -0.33 \\
\hline Sex & 0.60 & $1.28_{(297)}$ & .20 & -0.31 & 1.51 \\
\hline Region & 0.16 & $0.40_{(297)}$ & .69 & -0.60 & 0.92 \\
\hline Mental disorder history & 0.61 & 1.12 (297) & .26 & -0.45 & 1.67 \\
\hline COVID-19 contagion: No $v s$ Does not know and has no symptoms & -0.08 & $-0.18(297)$ & .86 & -0.93 & 0.77 \\
\hline COVID-19 contagion: No $v s$ Does not know but has symptoms & 0.64 & $0.81_{(297)}$ & .42 & -0.89 & 2.18 \\
\hline COVID-19 contagion: No $v s$ Yes & 0.54 & $0.97(297)$ & .33 & -0.54 & 1.61 \\
\hline Time (2) x COVID-19 contagion: No vs Does not know and has no symptoms & 1.09 & $2.16_{(297)}$ & $.03 *$ & 0.11 & 2.08 \\
\hline Time (2) x COVID-19 contagion: No vs Does not know but has symptoms & 2.33 & $2.55(297)$ & $.01 * *$ & 0.56 & 4.11 \\
\hline Time (2) x COVID-19 contagion: No vs Yes & 0.13 & 0.21 (297) & .83 & -1.11 & 1.38 \\
\hline
\end{tabular}

Note: $95 \%$ CI: $95 \%$ Confidence Intervals.

${ }^{a}$ All the additive effects tested, but only the predictors that presented at least one significant interaction in the model that best fitted the data are shown.

${ }^{\mathrm{b}}$ Exact $p$-values are given, except for p-values under 0.001 , which are given as $<0.001$. Statistically significant $p$-values are indicated as follows: $* p<.05 ; * * p \leq .01 ; * * p \leq .001$. 
Fixed Effects Modeling: Psychological Distress

We evaluated the need to analyze nested models by regions, but the inclusion of random effects was not statistically significant for psychological distress $\left(A I C_{\text {start }}=\right.$ 2161.4, $\left.A I C_{\text {final }}=2163.4, p>.99\right)$. Thus, the models that we built up included only fixed effects $\left(A I C_{\text {start }}=4179.55\right)$. We found a significant main effect of the age $\left(\chi_{(6)}^{2}=\right.$ $6.05, p=.01 ; A I C=4158.77, \log L i k=$ -2073.38) on psychological distress. The scores of psychological distress were higher in the younger age group $(<40$ years old), although with a small effect size $(E S=0.16)$. There was also a main effect of the time $\left(\chi^{2}\right.$ $(5)=18.73, p<.001 ; A I C=4163.82$, logLik $=-2076.41)$ and the mental disorder history $\left(\chi_{(9)}^{2}=12.43, p<.001\right.$; AIC = $4150.25, \log L i k=-2066.13)$ on psychological distress, but we did not interpret these main effects because there were significant interactions involving these main effects, which supersede it (see below). On the other hand, the levels of psychological distress were similar between the sexes $\left(\chi_{(7)}^{2}=\right.$ $1.96, p=.16 ; A I C=4158.82, \log L i k=$ $-2072.41)$, between the regions $\left(\chi_{(8)}^{2}=\right.$ $0.13, p=.72 ;$ AIC $=4160.69, \log$ Lik $=$ -2072.34), and by the COVID-19 contagion $\left(\chi_{(12)}^{2}=5.24, p=.15 ; A I C=4151.01\right.$, $\log L i k=-2063.51)$.

Furthermore, we found a significant interaction effect between time (the withinperson factor) and the COVID-19 contagion $\left(\chi_{(19)}^{2}=8.26, p=.04 ; A I C=4151.09\right.$, logLik $=-2056.54)$ on psychological distress. The contrasts revealed that, compared to those who had not been infected with the COVID-19, the psychological distress significantly increased from the first measurement to the follow-up in those who did not know if they had been infected with the COVID19 and had no symptoms of the disease $(b=$ 2.62, $\left.t_{(297)}=2.60, p=.01, E S=0.15\right)$. Instead, there were no differences in the psychological distress between both measurements in those who did not know if they had been infected with the COVID-19, but had symptoms of the disease $\left(b=2.17, t_{(297)}\right.$ $=1.19, p=.23)$ and in those who had gotten sick with COVID-19 $\left(b=0.10, t_{(297)}=0.08\right.$, $p=.94)$, when compared to those who had not been infected with the COVID-19.

Likewise, there was a significant interaction effect between the mental disorder history and the COVID-19 contagion $\left(\chi^{2}\right.$ $(37)=11.95, p=.008 ; A I C=4154.49$, logLik $=-2040.24)$ on psychological distress. The contrasts revealed that, in those that did not know if they had been infected with the COVID-19, but had symptoms of the disease, the psychological distress was higher among those without mental disorder history than those with such a background, when compared to their counterparts who had not been infected with the COVID-19 $\left(b=-14.18, t_{(279)}=-3.12, p=.002, E S=\right.$ $0.18)$. Instead, there were no differences in the psychological distress by the mental disorder history in those who did not know if they had been infected with the COVID-19 and had no symptoms of the disease $(b=$ $\left.-4.84, t_{(279)}=-1.93, p=.055\right)$ and in those who had gotten sick with COVID-19 $(b=$ $\left.-2.80, t_{(279)}=-0.68, p=.49\right)$, when compared to those who had not been infected with the COVID-19.

The remaining interactions that we tested were not meaningful $(p>.05$; data not shown). Table 5 summarizes the model best fitting the data on psychological distress.

\section{DISCUSSION}

This study describes the distribution of relevant variables, such as the selfperceived job performance level and the presence of symptoms compatible with common mental disorders, in a sample of healthcare workers during two time points of the COVID-19 pandemic. Likewise, this study examines the within-person changes in general discomfort and psychological distress of these healthcare workers, adjusting 
TABLE 5. Model Best Fitting the Psychological Distress in Healthcare Workers $(N=305)$

\begin{tabular}{|c|c|c|c|c|c|}
\hline \multirow[b]{2}{*}{ Predictors $^{a}$} & \multirow[b]{2}{*}{$b$} & \multirow[b]{2}{*}{$t_{(d f)}$} & \multirow[b]{2}{*}{$p^{\mathrm{b}}$} & \multicolumn{2}{|c|}{$95 \% C I$} \\
\hline & & & & Lower & Upper \\
\hline Intercept & 21.46 & 10.87 (297) & $<.001^{* * *}$ & 17.69 & 25.24 \\
\hline Time & 1.45 & 1.15 & .25 & -0.97 & 3.87 \\
\hline Age (younger) & -5.55 & $-2.65(279)$ & $.009 * *$ & -9.56 & -1.54 \\
\hline Sex & 2.08 & 1.00 & .32 & -1.91 & 6.07 \\
\hline Region & 1.32 & 0.58 & .56 & -3.05 & 5.70 \\
\hline Mental disorder history (presence) & 13.03 & $4.24_{(279)}$ & $<.001 * * *$ & 7.15 & 18.91 \\
\hline $\begin{array}{l}\text { COVID-19 contagion: No } v s \text { Does not know } \\
\text { and has no symptoms }\end{array}$ & -2.10 & $-0.83(279)$ & .41 & -6.96 & 2.75 \\
\hline $\begin{array}{l}\text { COVID-19 contagion: No } v s \text { Does not know } \\
\text { but has symptoms }\end{array}$ & 0.67 & $0.17_{(279)}$ & .86 & -6.64 & 7.97 \\
\hline COVID-19 contagion: No $v s$ Yes & 1.95 & $0.59(279)$ & .56 & -4.38 & 8.28 \\
\hline $\begin{array}{l}\text { Time (2) x COVID-19 contagion: No vs Does } \\
\text { not know and has no symptoms }\end{array}$ & 2.62 & $2.60_{(297)}$ & $.01 * *$ & 0.69 & 4.55 \\
\hline $\begin{array}{l}\text { Time (2) x COVID-19 contagion: No vs Does } \\
\text { not know but has symptoms }\end{array}$ & 2.17 & $1.19_{(297)}$ & .23 & -1.31 & 5.65 \\
\hline Time (2) x COVID-19 contagion: No vs Yes & 0.10 & 0.08 & .94 & -2.34 & 2.54 \\
\hline $\begin{array}{l}\text { Mental disorder history x COVID-19 } \\
\text { contagion: No } v \text { s Does not know and has } \\
\text { no symptoms }\end{array}$ & -4.84 & -1.93 (279) & .055 & -9.64 & -0.04 \\
\hline $\begin{array}{l}\text { Mental disorder history x COVID- } 19 \\
\text { contagion: No } v s \text { Does not know but has } \\
\text { symptoms }\end{array}$ & -14.18 & $-3.12_{(279)}$ & $.002 * *$ & -22.88 & -5.49 \\
\hline $\begin{array}{l}\text { Mental disorder history x COVID-19 } \\
\text { contagion: No } v s \text { Yes }\end{array}$ & -2.80 & $-0.68(279)$ & .49 & -10.63 & 5.02 \\
\hline
\end{tabular}

Note: $95 \%$ CI: $95 \%$ Confidence Intervals.

${ }^{a}$ All the additive effects tested, but only the predictors that presented at least one significant interaction in the model that best fitted the data are shown.

${ }^{\mathrm{b}}$ Exact $p$-values are given, except for $p$-values under 0.001, which are given as $<0.001$.

Statistically significant $p$-values are indicated as follows: $* p<.05 ; * * p \leq .01 ; * * * \leq .001$.

for main demographic factors, region, and relevant health-related factors.

In descriptive group terms, the level of self-perceived job performance deteriorated from the first to the second measurement. Additionally, in the latter, a higher percentage of healthcare workers had levels of general discomfort and psychological distress compatible with mental disorders. The possibility exists that both aspects are linked, since the presence of mental disorders has been associated with detrimental work performance (Ashtari et al., 2009; Parker \& Kulik, 1995). Likewise, it is possible that this decline in selfperception of the job performance level is associated with additional factors which were not directly evaluated in our study, such as work overload and organizational factors (Muller et al., 2020; Posenato Garcia et al., 2010), poor social support (Spoorthy et al., 2020), and moral injury (Greenberg et al., 2020), among others. Before the pandemic, healthcare workers tend to have, in general, longer working hours, heavier psychological demands, and may have a higher prevalence of mental disorders than individuals who work in non-healthcare areas (Cheng \& Cheng, 2017). However, in many countries, healthcare systems were not well prepared to face a pandemic, such as COVID-19 and this implied an exceedingly larger workload for healthcare workers. As Greenberg et al. (2020) noted, even in the best-prepared countries, this pandemic put 
healthcare workers in an unprecedented situation, where they must sustain healthcare under high-pressure conditions and, at times, must decide on how to allocate scarce resources to equally reliant patients. In parallel, they must decide how to balance the pressing work demands with their own needs physical and mental- and their family needs. Among other important consequences, all these aspects may lead to experiencing moral injury in some healthcare workers. Those who suffer from moral injury are likely to experience negative thoughts about themselves or others, along with deep feelings of shame, guilt or disgust (Greenberg et al., 2020), all of which may contribute to a greater psychological discomfort and a worse perception of one's own job performance.

At the time when we made the first measurement, almost no cases of COVID-19 had been registered from the inside area of the country that we sampled, while cases were high and rising in the metropolitan area. By the time of the follow-up, both areas of the country have registered their highest peaks of COVID-19 contagion. The observation of an increase in anxiety and/or depression disorders reported from the inside country area (Jujuy) may be attributed to a more pronounced sanitary change, as compared to the metropolitan area. There are studies reporting the highest prevalence of anxiety symptoms in medical staff working in the worst affected areas for the COVID-19 pandemic (Liang et al., 2020; C. Y. Liu et al., 2020). During both time-points of our study, we have found a higher prevalence of healthcare workers with common mental disorders $(40 \%$ and $45.57 \%, 1^{\text {st }}$ and $2^{\text {nd }}$ measurement respectively), such as depression and/or anxiety $\left(52.46 \%\right.$ and $62.62 \%, 1^{\text {st }}$ and $2^{\text {nd }}$ measurement respectively), than what was reported during the current pandemic in healthcare workers from other countries. In Asian countries, a pooled prevalence of $22.8 \%$ for depression and $23.2 \%$ for anxiety was reported, according to a systematic review and meta-analysis (Pappa et al., 2020).
However, upon reviewing individual studies of the meta-analysis, for instance, one study reported depressive and anxiety symptoms in $50.4 \%$ and $44.6 \%$ of healthcare workers, respectively (Lai et al., 2020). The broad differences in prevalence of psychological symptoms in healthcare workers may be due to the different tools used and the different stages of the pandemic in which the measurements were made (Leung et al., 2005; C. Y. Liu et al., 2020). Likewise, psychological symptoms would be the highest among frontline healthcare workers (Que et al., 2020). Remarkably, our sample is mostly composed of healthcare workers providing face-to-face patient assistance in health institutions $(75.41 \%)$. Nevertheless, additional factors, such as inadequate protection supplies and insufficient human resources to rotate staff, may be critical to the higher prevalence of psychological symptoms registered in developing countries as compared to developed countries.

According to the univariate analysis, the psychological distress in healthcare workers increased significantly from the first measurement to the follow-up, while the levels of general discomfort remained constant between both measurements. However, the mixed modeling effects showed that the within-person changes in mental health state in the context of this pandemic is a complex phenomenon and that, beyond mental health measurements, additional factors need to be included in the analyses for further understanding. For instance, we found that age is a variable exerting main effects on both general discomfort and psychological distress in healthcare workers. However, this effect would not be exclusive of the healthcare workers sub-group, since this effect was also observed in women during the COVID-19 pandemic (López Steinmetz et al., 2020), as well as in the general population (Pierce et al., 2020). This is interesting, because while the severity of the COVID-19 disease and its mortality are the highest among the oldest (K. Liu et al., 2020), the negative mental health outcomes 
of this pandemic seem to be the highest among the youngest. Regarding sex, unlike studies that have found a higher burden of depressive and anxiety disorders among women healthcare workers (Muller et al., 2020; Pappa et al., 2020), we did not find a main effect of this factor on the mental health indicators that we measured in our study. However, our sample was sex unbalanced and this could have biased our findings in this regard. Finally, the region neither had a main effect on general discomfort nor psychological distress.

Along with the main effects, we found meaningful interactions between some factors that we analyzed, which explained part of the changes registered in the mental health of the healthcare workers. In this regard, although high levels of psychological symptoms predominated in the two measurements, changes in mental health over time were mediated by the factor defined as COVID-19 contagion. The meaningful worsening of mental health occurred in healthcare workers who did not know if they had been infected with COVID-19, whether they did not have symptoms of this disease (greater general discomfort and psychological distress) or if they had them (greater general discomfort). These findings suggest that a component of uncertainty about the COVID-19 contagion would pose as a heavier factor on the detriment of the mental health state in healthcare workers than the actual contagion. A cross-sectional study on medical staff during the COVID-19 outbreak in China found that those who had direct clinical contact with infected patients and those who were suspect cases experienced the highest anxiety symptoms (C. Y. Liu et al., 2020). In addition, we found that the level of psychological distress in healthcare workers differs in the light of the interaction between the mental disorder history and COVID-19 contagion factors. Strikingly, in the group that was not sure if they had been infected with COVID-19, but had symptoms of this disease, those without mental disorder history were more vulnerable to developing higher levels of psychological distress than those having such a background. These results may be due to a number of factors not directly assessed in our study. For instance, individual differences, such as higher tendencies to feel fear of the COVID-19 contagion and of their potential consequences and subjective perception of psychological aspects (Di Crosta et al., 2020), which may be relevant in the differences registered between healthcare workers without and with mental disorder background. The perceived threat of the COVID-19 contagion (emotional and cognitive threat) positively correlates with physiological anxiety, depression, and emotional exhaustion (Shahzad et al., 2020). In this regard, it is important to bear in mind that a variety of self-awareness deficits have been described as features of some mental disorders, namely schizophrenia, but also schizoaffective disorder, bipolar disorder, and major depressive disorders, among others (Amador et al., 1994; Pini et al., 2001), which could have influenced the development of a lower psychological distress against the potential COVID-19 contagion in healthcare workers with mental disorder background compared to those without such a background. Unfortunately, to date, we have not found longitudinal studies published in peer-reviewed journals reporting within-person changes on mental health outcomes in healthcare workers during the COVID-19 pandemic, with which to compare our findings. We have only found the study of Cai et al. (2020) which focused exclusively on nurses, although having a longitudinal design with two measurements, it could not match the questionnaires to the individuals in both measurements, and thus not providing information on the within-person changes in the mental health state.

\section{Limitations}

This study has several strengths; notably, a longitudinal design with a low attrition between the two measurements, the use of 
validated screening tools for the mental health outcomes assessment, and the identification of potential contributory factors linked to these outcomes in healthcare workers, an essential group at the frontlines of the COVID-19 pandemic. However, these findings should be considered in light of some limitations. First, sampling was one of convenience and represents only two Argentinean regions. Although this sample included data of healthcare workers from well-balanced metropolitan and nonmetropolitan or rural areas, these results may not be generalizable to all regions, and further studies based on probabilistic larger samples are necessary. Furthermore, the region of residence was asked at the first measurement, thus implying that if individuals moved after the initial assessment, we could not take this change into consideration. Second, the sample was sex unbalanced (women predominated). However, it is important to bear in mind that among Argentinean healthcare workers, women are also in the majority $(59.3 \%)$ (PUND, 2018). Third, levels of symptoms compatible with common mental disorders, depression, and/or anxiety were based on selfadministered questionnaires, but no psychiatric interviews were carried out. Although we utilized validated and widely used scales, which have intrinsic values as indicators of these mental health outcomes, it is important to take into account that our findings on mental disorders are based on self-report measures, which is an additional limitation. Fourth, we did not evaluate the prevalence of psychological symptoms among healthcare workers before COVID-19 pandemic and inferences regarding such prevalence cannot be drawn from our data. In addition, this prevalence remains unknown in Argentina. Fifth, although the entire sample was composed by healthcare workers, their composition was heterogeneous and some particular stress factors (e.g., work in direct contact with COVID-19 positive patients) may have affected mental health in different ways depending on the kind of tasks involved. Sixth, there may be additional unmeasured factors that may also explain part of the withinperson changes in mental health among healthcare workers, some of which we have discussed earlier in this paper.

\section{Implications}

To the best of our knowledge, this is the first longitudinal study examining the within-person changes in the mental health state of healthcare workers during two time points of the COVID-19 pandemic, of which the second one was during a peak of the pandemic. Notwithstanding the aforementioned limitations, this research provides valuable knowledge on the dynamic of mental health outcomes in healthcare workers under conditions of the COVID-19 pandemic and identifies contributory factors leading to worst outcomes. For instance, the uncertainty about COVID-19 contagion is a significant, although preventable, factor linked to worsening of mental health outcomes in healthcare workers, thus suggesting that by providing more COVID-19 tests, may reduce their uncertainties and, consequently, lowering the burden of some mental disorders. These findings may be useful for public health officials and government officials who must decide upon healthcare investments and who must respond appropriately and proportionately to mitigate the undesired side effects of work overload on healthcare workers due to the COVID-19 pandemic.

\section{ACKNOWLEDGMENTS}

We thank participants for taking the time to contribute to this study. We also wish to acknowledge all healthcare workers for their commitment with the care of patients, families, and our community during the COVID-19 pandemic. 


\section{FUNDING}

This research received no specific grant from any funding agency, commercial or not-forprofit sectors. All authors have no financial disclosures to declare.

\section{DISCLOSURE STATEMENT}

No potential conflict of interest was reported by the authors.

\section{DATA AVAILABILITY STATEMENT}

The data that support the findings of this study are available at the OSF (Open Science Framework) repository, https://doi. org/10.17605/OSF.IO/UCYE7

\section{ORCID}

Lorena Cecilia López Steinmetz http://orcid.org/0000-0001-6255-4031

Shao Bing Fong (D) http://orcid.org/ 0000-0002-0065-7884

Juan Carlos Godoy (i) http://orcid.org/ 0000-0002-1622-1647

\section{REFERENCES}

Amador, X. F., Flaum, M., Andreasen, N. C., Strauss, D. H., Yale, S. A., Clark, S. C., \& Gorman, J. M.. (1994). Awareness of illness in schizophrenia and schizoaffective and mood disorders. Archives of General Psychiatry, 51(10), 826-836. https://doi.org/10.1001/archpsyc.1994. 03950100074007

Ashtari, Z., Farhady, Y., \& Khodaee, M. R. (2009). Relationship between job burnout and work performance in a sample of Iranian mental health staff. African Journal of Psychiatry, 12(1), 71-74. https://doi.org/10.4314/ajpsy.v12i1. 30282

Brenlla, M., \& Aranguren, M. (2010). Adaptación Argentina de la Escala de Malestar Psicológico de Kessler (K10) [Argentine adaptation of the Kessler Psychological Discomfort Scale (K10]. Revista de Psicología, 28(2), 309-340. https://doi.org/10.18800/psico.201002.005

Brown, T. A. (2006). Confirmatory factor analysis for applied research. Guilford Press.

Burrone, M. S., Abeldaño, A., Susser, L., Lucchese, M., Enders, J., Alvarado, R., Valencia, E., \& Fernandez, R. (2015). Evaluación psicométrica y estudio de fiabilidad del Cuestionario General de Salud (GHQ-12) en consultantes adultos del primer nivel de atención en Córdoba, Argentina [Psychometric evaluation and reliability study of the General Health Questionnaire (GHQ-12) in adult consultants of the first level of care in Córdoba, Argentina]. Revista de la Facultad de Ciencias Médicas de Córdoba, 72(4), 236-242.

Cai, Z., Cui, Q., Liu, Z., Li, J., Gong, X., Liu, J., Wan, Z., Yuan, X., Li, X., Chen, C., \& Wang, G. (2020). Nurses endured high risks of psychological problems under the epidemic of COVID-19 in a longitudinal study in Wuhan China. Journal of Psychiatric Research, 131, 132-137. https://doi. org/10.1016/j.jpsychires.2020.09.007

Cheng, W. J., \& Cheng, Y. (2017). Minor mental disorders in Taiwanese healthcare workers and the associations with psychosocial work conditions. Journal of the Formosan Medical Association, 116(4), 300-305. https://doi.org/10. 1016/j.jfma.2016.05.004

Di Crosta, A., Palumbo, R., Marchetti, D., Ceccato, I., La Malva, P., Maiella, R., Cipi, M., Roma, P., Mammarella, N., Verrocchio, M. C., $\&$ Di Domenico, A. (2020). Individual differences, economic stability, and fear of contagion as risk factors for PTSD symptoms in the COVID-19 emergency. Frontiers in Psychology, 11, 567367. https://doi.org/10.3389/fpsyg.2020. 567367

Donker, T., Comijs, H., Cuijpers, P., Terluin, B., Nolen, W., Zitman, F., \& Penninx, B. (2010). The validity of the Dutch K10 and extended K10 screening scales for depressive and anxiety disorders. Psychiatry Research, 176(1), 45-50. https://doi.org/10.1016/j.psychres.2009.01.012 
Field, A., Miles, J., \& Field, Z. (2012). Discovering statistics using $R$. SAGE.

Goldberg, D. P., Gater, R., Sartorius, N., Ustun, T. B., Piccinelli, M., Gureje, O., \& Rutter, C. (1997). The validity of two versions of the GHQ in the WHO study of mental illness in general health care. Psychological Medicine, 27(1), 191-197. https://doi.org/10.1017/ s0033291796004242

Greenberg, N., Docherty, M., Gnanapragasam, S., \& Wessely, S. (2020). Managing mental health challenges faced by healthcare workers during covid-19 pandemic. BMJ, 368, m1211. https:// doi.org/10.1136/bmj.m1211

Kessler, R. C., Andrews, G., Colpe, L. J., Hiripi, E., Mroczek, D. K., Normand, S. L. T., Walters, E. E., \& Zaslavsky, A. M. (2002). Short screening scales to monitor population prevalences and trends in non-specific psychological distress. Psychological Medicine, 32(6), 959-976. https:// doi.org/10.1017/S0033291702006074

Kessler, R. C., \& Mrozek, D. K. (1994). Final version of our own non-specific Psychological Distress Scale. University of Michigan.

Lai, J., Ma, S., Wang, Y., Cai, Z., Hu, J., Wei, N., Wu, J., Du, H., Chen, T., Li, R., Tan, H., Kang, L., Yao, L., Huang, M., Wang, H., Wang, G., Liu, Z., $\& \mathrm{Hu}$, S. (2020). Factors associated with mental health outcomes among health care workers exposed to coronavirus disease 2019. JAMA Network Open, 3(3), e203976. https://doi.org/10. 1001/jamanetworkopen.2020.3976

Leung, G. M., Ho, L. M., Chan, S. K. K., Ho, S. Y., Shone, J. B., Choy, R. Y. L., Hedley, A. J., Lam, T. H., \& Fielding, R. (2005). Longitudinal assessment of community psychobehavioral responses during and after the 2003 outbreak of severe acute respiratory syndrome in Hong Kong. Clinical Infectious Diseases, 40(12), 1713-1720. https://doi.org/10.1086/429923

Liang, Y., Wu, K., Zhou, Y., Huang, X., Zhou, Y., \& Liu, Z. (2020). Mental health in frontline medical workers during the 2019 novel coronavirus disease epidemic in China: A comparison with the general population. International Journal of Environmental Research and Public Health, 17(18), 6550. https://doi.org/10. 3390/ijerph17186550
Liu, C. Y., Yang, Y. Z., Zhang, X. M., Xu, X., Dou, Q. L., Zhang, W. W., \& Cheng, A. S. K. (2020). The prevalence and influencing factors in anxiety in medical workers fighting COVID-19 in China: A cross-sectional survey. Epidemiology and Infection, 148, e98. https://doi.org/10.1017/ s0950268820001107

Liu, K., Chen, Y., Lin, R., \& Han, K. (2020). Clinical features of COVID-19 in elderly patients: A comparison with young and middle-aged patients. The Journal of Infection, 80(6), e14e18. https://doi.org/10.1016/j.jinf.2020.03.005

López Steinmetz, L. C., Fong, S. B., Leyes, C. A., Dutto Florio, M. A., \& Godoy, J. C. (2020). General mental health state indicators in Argentinean women during quarantine of up to 80-day duration for COVID-19 pandemic. Frontiers in Global Women's Health, 1. Advance online publication. https://doi.org/10.3389/fgwh.2020. 580652

Muller, A. E., Hafstad, E. V., Himmels, J. P. W., Smedslund, G., Flottorp, S., Stensland, S. Ø., Stroobants, S., Van de Velde, S., \& Vist, G. E. (2020). The mental health impact of the covid-19 pandemic on healthcare workers, and interventions to help them: A rapid systematic review. Psychiatry Research, 293, 113441. https://doi. org/10.1016/j.psychres.2020.113441

Pappa, S., Ntella, V., Giannakas, T., Giannakoulis, V. G., Papotusi, E., \& Katsaounou, P. (2020). Prevalence of depression, anxiety, and insomnia among healthcare workers during the COVID-19 pandemic: A systematic review and meta-analysis. Brain, Behavior, and Immunity, 88, 901-907. https://doi.org/10.1016/j. bbi.2020.05.026

Parker, P. A., \& Kulik, J. A. (1995). Burnout, self- and supervisor-rated job performance, and absenteeism among nurses. Journal of Behavioral Medicine, 18(6), 581-599. https://doi.org/10. 1007/BF01857897

Pierce, M., Hope, H., Ford, T., Hatch, S., Hotopf, M., John, A., Kontopantelis, E., Webb, R., Wessely, S., McManus, S., \& Abel, K. M. (2020). Mental health before and during the COVID-19 pandemic: A longitudinal probability sample survey of the UK population. The Lancet. Psychiatry, 7(10), 883-892. https:// doi.org/10.1016/s2215-0366(20)30308-4 
Pinheiro, J., Bates, D., DebRoy, S., \& Sarkar, D., \& R Core Team. (2020). nlme: Linear and nonlinear mixed effects models. $R$ package (version 3.1-149). [Computer software]. https://CRAN. R-project.org/package $=$ nlme

Pini, S., Cassano, G. B., Dell'Osso, L., \& Amador, X. F. (2001). Insight into illness in schizophrenia, schizoaffective disorder, and mood disorders with psychotic features. The American Journal of Psychiatry, 158(1), 122-125. https:// doi.org/10.1176/appi.ajp.158.1.122

Posenato Garcia, L., Höfelmann, D. A., \& Facchini, L. A. (2010). Self-rated health and working conditions among workers from primary health care centers in Brazil. Cadernos De Saude Publica, 26(5), 971-980. https://doi.org/10.1590/ s0102-311x2010000500019

Programa de las Naciones Unidas para el Desarrollo. (2018). Aportes para el desarrollo humano en Argentina 2018: Género en el sector salud: Feminización $y$ brechas laborales [Contributions to human development in Argentina 2018: Gender in the health sector: Feminization and labor gaps].

Que, J., Shi, L., Deng, J., Liu, J., Zhang, L., Wu, S., Gong, Y., Huang, W., Yuan, K., Yan, W., Sun, Y.,
Ran, M., Bao, Y., \& Lu, L. (2020). Psychological impact of the COVID-19 pandemic on healthcare workers: A cross-sectional study in China. General Psychiatry, 33(3), e100259. https://doi.org/10. 1136/gpsych-2020-100259

R Core Team. (2020). R: A language and environment for statistical computing. [Computer software]. R Foundation for Statistical Computing. https://www.R-project.org/

Shahzad, F., Du, J., Khan, I., Fateh, A., Shahbaz, M., Abbas, A., \& Wattoo, M. U. (2020). Perceived threat of COVID-19 contagion and frontline paramedics' agonistic behaviour: Employing a stressor-strain-outcome perspective. International Journal of Environmental Research and Public Health, 17(14), 5102. https://doi.org/ 10.3390/ijerph17145102

Spoorthy, M. S., Pratapa, S. K., \& Mahant, S. (2020). Mental health problems faced by healthcare workers due to the COVID-19 pandemic - A review. Asian Journal of Psychiatry, 51, 102119. https://doi. org/10.1016/j.ajp.2020.102119

Worldometer. (2020). COVID-19 Coronavirus Pandemic. Retrieved November 6, 2020, from https://www.worldometers.info/coronavirus/ 